\title{
Alternative Management Strategies for Tomato Affect Cultural and Economic Sustainability
}

\author{
S.B. Sterrett, ${ }^{1}$ H.E. Hohlt, and C.P. Savage, Jr. \\ Eastern Shore Agricultural Research and Extension Center, Virginia Polytechnic \\ Institute and State University, Painter, VA 23420 \\ Additional index words. plasticulture, best management practices, organic mulch
}

Abstract. Off-site movement of sediment, nutrient and agricultural chemicals from plasticulture production of green-pack tomatoes on water quality is a serious environmental concern, particularly for the clam aquaculture industry of eastern Virginia. Thus, the development of ecologically sound, economically sustainable cultural management strategies for tomato (Lycopersicon esculentum Mill.) production is needed. Two plantings were made within each of the three tomato harvest seasons [summer, bridge (late summer) and fall] in 1998 and 1999 (one summer crop in 1999). Between-bed treatments included clean culture or pearl millet [Pennisetum glaucum(L.) R. Br.] sown at bed establishment. On-bed treatments included standard plasticulture with fumigation on a $76-\mathrm{cm}$-wide bed (std), plasticulture without fumigation on a 76-cm-wide bed (std-fum), plasticulture on a 61-cmbed with fumigation (narrow) and organic mulch [wheat straw (Triticum aestivum L.) in 1998; desiccated hairy vetch (Vicia villosa Roth.) in 1999]. Total and marketable yields for the three plasticulture on-bed treatments (std, std-fum and narrow) were similar in 1998 and 1999. Yield was suppressed for the organic mulch on-bed treatments in all but the bridge plantings in 1999. Improved yield with plasticulture treatments and high market price for the summer crop in 1998 resulted in elevated crop value and return to land and management (return) compared to that of organic mulch. The return for later plantings was low, but positive. Return was negative for both bridge and the first fall crops in organic mulch in 1998. Low yields in all treatments and low prices in 1999 resulted in negative to negligible return for on-bed treatments in all but the summer planting using plasticulture. Return was consistently lower with organic mulch compared to plasticulture for the high value summer crop in Virginia with between-bed millet in 1998 and with or without millet in 1999. The use of organic mulch on the beds in this study was not economically feasible for the high value summer crops. Adjustments (desiccation of cover, control of weeds) in cultural management of the between-bed management strategy are needed before largescale commercial implementation will occur.

Plasticulture tomato productionhas beenused on the Eastern Shore of Virginia since the early 1980 's with nearly 6,000 acres planted annually. Commercial production includes three harvest seasons: summer, late summer (bridge), and fall. The advantages of increased crop yield using the plasticulture system of polyethylene mulch, soil fumigation, and drip irrigation have been well documented (Bhella, 1988; Bogle et al., 1989; Perry and Sanders, 1986; VanDerwerken and Wilcox-Lee, 1988; Wien and Minotti, 1987). The use of plasticulture also results in water conservation (Bogle et al., 1989; VanDerwerken and Wilcox-Lee, 1988), reduced nutrient movement (Bottcher et al., 1982), and suppression of weeds (Brault et al., 2002; Teasdale and Colacicco, 1985). However, up to $55 \%$ of the production area may be covered with polyethylene mulch,

Received for publication 17 Aug. 2004. Accepted for publication 15Oct. 2004. This projectfunded, in part, by the Chesapeake Bay Restoration Fund Advisory Committee, Richmond, Va., and the Virginia Agricultural Council. The assistance of J.T. Custis and the farm crew in establishing and maintaining the research plots is greatly appreciated. We thank K.G. Haynes and R. Veilleux for editing early version of this manuscript. Use of company or product names by Virginia Tech does not imply approval or recommendation of the product to the exclusion of others that may be suitable. ${ }^{1}$ Corresponding author. reducing waterinfiltration and promoting off-site (Scott et al., 1990).

The tidal waters surrounding Virginia's Eastern Shore are important nurseries for fish and shellfish, including the high-value clam (Mercenariamercenaria L.) aquaculture industry (Arnold et al., 2001). The need to promote ecologically sound tomato production strategies in this growing area was highlighted by a controversy between tomato plasticulture producers and the clam aquaculture industry (Courter et al., 1998). Concerns included off-site sediment, nutrient and agricultural chemical movement that may adversely impact estuarine habitats. Since both tomato production and clam aquaculture are economically important to the Eastern Shore, the long-term challenge is to promote tomato production management strategies that allow these industries to coexist.

Wolfe et al. (2002) has compiled a list of potential best management practices (BMPs) for plasticulture in Virginia. A BMP is defined as a practice, or system of practices designed to control nonpoint source pollution with the effectiveness being a function of site-specific conditions including topography, soil properties, and vegetative cover (Wolfe et al., 2002).

Several short, intermediate and long-term movement of nutrients, pesticides and sediments
BMPs were recommended by the Interagency Plasticulture Task Force Conservation/Best Management Practices Subcommittee (Courter et al., 1998). These included using desiccated organic mulches instead of polyethylene film mulch, reducing the bed width, and developing integrated pest management plans for more efficient use of pesticides. The benefits of using organic mulch instead of plastic mulch include reduced soil erosion, reduced need for inorganic nutrients, improved soil organic matter, and increased soil water-holding capacity (Abdul-Baki and Teasdale, 1997). Hairy vetch has been preferred as a cover crop in several studies (Abdul-Baki and Teasdale, 1997; Kelly et al., 1995; Morse, 2001). However, delayed fruit maturity has been associated with vetch due to cooler soil temperatures early in the growing season (Teasdale and Abdul-Baki, 1995).

Jaworski etal.(1981) reported no significant difference in tomato yield between fumigated, plastic-covered beds that were 56,84 , or $112 \mathrm{~cm}$ wide although yield was reduced at bed widths $<56 \mathrm{~cm}$. Also, root-knot nematodes (Meloidogyne incognita Kofoid and White), parasitic soil fungi (Fusarium spp, Pythium spp, and Rhizoctonia solani Kuhn), and root-galls decreased with increased fumigated bed width (Jaworski et al., 1981). The potential loss of methyl bromide for fumigation under plastic mulch has growers concerned. Although fumigation is recommended to control nematodes and yellow nutsedge (Cyperus esculentus L.), the potential impact of not fumigating in the absence of these problems is unknown. Although runoff and the associated sediment load may theoretically be reduced with individualBMPs or combinations, commercial adoption will depend upon the impact of BMP implementation on crop yield and economic return. The impact of combinations of the proposed BMPs on yield, fruit quality, and economic return of the high-value tomato crop has not been determined. The purpose of this study was to examine the influence of potential BMP's on yield, value and net return to the grower for the spring, bridge and fall tomato seasons on Virginia's Eastern Shore.

\section{Materials and Methods}

Trials were planted in a split-split plot design with planting date as the main plot, between-bed treatment as the subplot and on-bed treatment as the sub-subplot with four replications. The plots were established on a Bojac sandy loam soil (coarse-loamy, mixed thermic Typic Hapludult) at the Eastern Shore AREC on the Delmarva Peninsula. The trials included six plantings in 1998 and five plantings in 1999 at about 15-d intervals. In 1998, two plantings were made in summer (summer-1, summer-2), bridge (bridge1, bridge-2), and fall(fall-1, fall-2) seasons (Table 1). In 1999, the first summer planting (summer-1) was omitted due to excessive rain; an additional $97 \mathrm{~mm}$ of rain between 12 and 22 June delayed planting of the first fall crop until 28 June.

Between-bed treatments compared clean culture to pearl millet planted between beds when the plastic was laid (Table 1). Height of the millet was maintained below $20 \mathrm{~cm}$ by periodic mowing. On-bed treatments included 
Table 1. Planting dates, harvest dates, and cultural practices for tomato trials in 1998 and 1999.

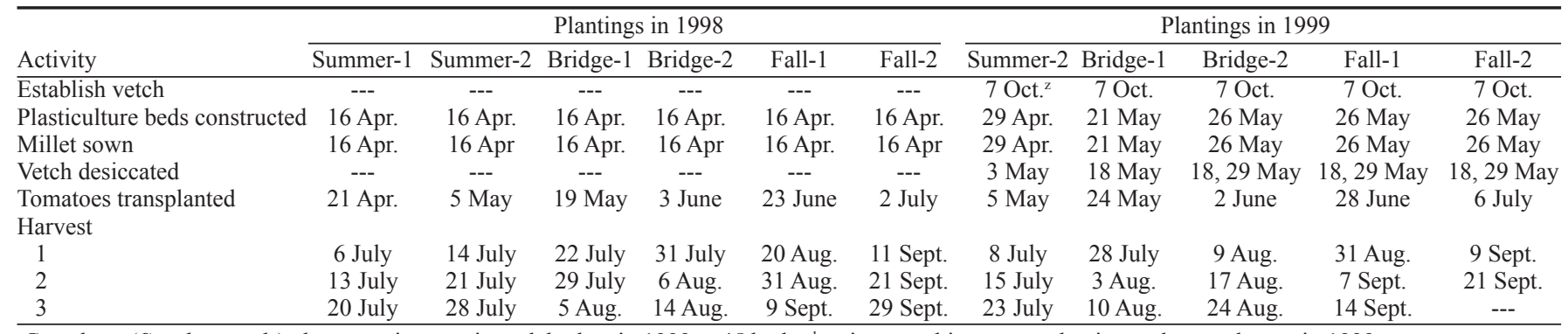

${ }^{2}$ Cereal rye (Secale cereale) also sown in organic mulch plots in 1999 at $45 \mathrm{~kg} \cdot \mathrm{ha}^{-1}$ to increase biomass production and groundcover in 1999.

Table 2. Statistical analyses of yield, value and return to land and management shown in Figs. 1, 3, and 4.

\begin{tabular}{|c|c|c|c|}
\hline Parameter & Factor & 1998 & 1999 \\
\hline \multirow[t]{8}{*}{ Total yield } & Planting date (PD) (main plot) & $* * *$ & **** \\
\hline & Between-bed cover (BB) (subplot) & $* * *$ & NS \\
\hline & $\mathrm{PD} \times \mathrm{BB}$ & ** & NS \\
\hline & On-bed treatments (OB) (sub-subplot) & $* * *$ & $* * *$ \\
\hline & $\mathrm{PD} \times \mathrm{OB}$ & $* * *$ & $* * *$ \\
\hline & $\mathrm{BB} \times \mathrm{OB}$ & NS & NS \\
\hline & $\mathrm{PD} \times \mathrm{BB} \times \mathrm{OB}$ & NS & * \\
\hline & $\mathrm{CV}(\%)$ & 13.0 & 14.4 \\
\hline \multirow[t]{8}{*}{ Marketable yield } & Planting date (PD) (main plot) & $* * *$ & $* * *$ \\
\hline & Between-bed (BB) (subplot) & $* * *$ & NS \\
\hline & $\mathrm{PD} \times \mathrm{BB}$ & * & NS \\
\hline & On-bed (OB) (sub-subplot) & $* * *$ & $* * *$ \\
\hline & $\mathrm{PD} \times \mathrm{OB}$ & $* * *$ & $* * *$ \\
\hline & $\mathrm{BB} \times \mathrm{OB}$ & * & NS \\
\hline & $\mathrm{PD} \times \mathrm{BB} \times \mathrm{OB}$ & NS & * \\
\hline & $\mathrm{CV}(\%)$ & 15.5 & 15.6 \\
\hline \multirow[t]{8}{*}{ Crop value } & Planting date (PD) (main plot) & $* * *$ & $* * *$ \\
\hline & Between-bed (BB) (subplot) & ** & NS \\
\hline & $\mathrm{PD} \times \mathrm{BB}$ & * & NS \\
\hline & On-bed (OB) (sub-subplot) & $* * *$ & $* * *$ \\
\hline & $\mathrm{PD} \times \mathrm{OB}$ & $* * *$ & $* * *$ \\
\hline & $\mathrm{BB} \times \mathrm{OB}$ & ** & NS \\
\hline & $\mathrm{PD} \times \mathrm{BB} \times \mathrm{OB}$ & $* * *$ & $*$ \\
\hline & CV $(\%)$ & 17.4 & 15.6 \\
\hline \multirow{8}{*}{ Return to land and management } & Planting date (PD) (main plot) & $* * *$ & *** \\
\hline & Between-bed (BB) (subplot) & ** & NS \\
\hline & $\mathrm{PD} \times \mathrm{BB}$ & * & NS \\
\hline & On-bed (OB) (sub-subplot) & $* * *$ & $* * *$ \\
\hline & $\mathrm{PD} \times \mathrm{OB}$ & $* * *$ & $* * *$ \\
\hline & $\mathrm{BB} \times \mathrm{OB}$ & ** & NS \\
\hline & $\mathrm{PD} \times \mathrm{BB} \times \mathrm{OB}$ & ** & * \\
\hline & $\mathrm{CV}(\%)$ & 33.0 & $-195^{z}$ \\
\hline
\end{tabular}

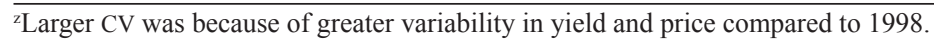

1) standard plasticulture (black-on-white embossed plastic for spring plantings, whiteon-black embossed plastic for bridge and fall on $75 \mathrm{~cm}$ bed + fumigation $\left(224 \mathrm{~kg} \cdot \mathrm{ha}^{-1} 67 \%\right.$ methyl bromide $/ 33 \%$ chloropicrin) (std); 2) plasticulture without fumigation (std-fum); 3) plasticulture on $60-\mathrm{cm}$ bed (narrow); and 4) organic mulch. All treatments included trickle irrigation. Excessive rainfall in late September and October 1997, prevented timely establishment of hairy vetch for the 1998 plantings. As an alternative, straw (64-mm depth) was applied to the beds after tomatoes were transplanted to provide the organic mulch. Netting was needed to hold the straw on the beds (BaleBind International, Dubuque, Iowa 52001). Hairy vetch (sown at rate of $45 \mathrm{~kg} \cdot \mathrm{ha}^{-1}$ ) was established in Fall 1998 for the 1999 season with cereal rye (Secale cereale L.) sown at $45 \mathrm{~kg} \cdot \mathrm{ha}^{-1}$ in the first two plantings for increased biomass production (Table 1). Vetch sown in the organic mulch treatment was chemically desiccated (paraquat, $0.63 \mathrm{~kg} \cdot \mathrm{ha}^{-1}$ a.i.) before planting for the first two plantings. For the last four plantings, vetch was in early bloom when chemically desiccated. Further delay in desiccation would have resulted in production of mature vetch seed, hence increasing vetch as a weed species in succeeding crops (Bratsch et al., 2004).

Lycopersicom esulentum 'Sun Leaper' was used for all plantings. Transplants of this heattolerant cultivar were grown from seed sown in Sunshine Mix\#1 (Sun Grow Horticulture, Bellevue, Wash.) using 105-cell (width $\times$ width $\times$ height: $41 \times 41 \times 75 \mathrm{~mm}$ ) polystyrene transplant flats (Speedling, Sun City, Fla.) 5 to 7 weeks before target planting dates (shorter time for later plantings) and transplants hardened-off for at least one week before field planting.

A total of $56 \mathrm{~kg} \cdot \mathrm{ha}^{-1} \mathrm{~N}, 24.5 \mathrm{~kg} \cdot \mathrm{ha}^{-1} \mathrm{P}$ and $46.5 \mathrm{~kg} \cdot \mathrm{ha}^{-1} \mathrm{~K}$ was incorporated into the beds of all treatments in 1998 and all plasticulture on-bed treatments in 1999 . Vetch beds were top dressed at the same rate. All plots received $112 \mathrm{~kg} \cdot \mathrm{ha}^{-1} \mathrm{~N}$ and $224 \mathrm{~kg} \cdot \mathrm{ha}^{-1} \mathrm{~K}$ by fertigation. Single row plots were $6.4 \mathrm{~m}$ in length with 46 $\mathrm{cm}$ between plants. Tomato plants were maintained using short (1.5-m length) stakes and the Florida weave trellis with a stake between every other plant. Each planting was harvested three times, except the last planting in 1999. In total, $13.7 \mathrm{~cm}$ of rain fell during and after Hurricane Floyd (14 to 17 Sept. 1999) causing damage and deterioration of the tomato vines, eliminating the third harvest. The harvested area consisted of six consecutive plants per plot $(2.7 \mathrm{~m})$. Fruit was harvested at the mature green stage and sized into grades: small (54 to $58 \mathrm{~mm}$ ), medium (58 to $64 \mathrm{~mm}$ ), large (64 to $71 \mathrm{~mm})$ and extra large $(>71 \mathrm{~mm})$ (U.S. Dept. of Agriculture, Agricultural marketing Service, 1992). Fruit $<58 \mathrm{~mm}$ are commercially considered culls and not sold.

Daily maximum and minimum temperatures and rainfall were recorded at the Eastern Shore AREC (official NOAA weather station). Accumulated heat units (base $10^{\circ} \mathrm{C}$ ) were calculated for each planting in the 1998 and 1999 growing seasons (Fig. 1). Monthly rainfall from May to September 1998 was $156 \%, 136 \%, 63 \%, 54 \%$, and $151 \%$ of the 63 -year average, respectively, for The Eastern Shore AREC (official NOAA weather station). Monthly rainfall for the same period in 1999 was $30,122,57,112$, and 290 (primarily from Hurricanes Dennis and Floyd) percent of the 63-year average, respectively.

The market value was determined for each marketable size at each harvest, using FOB prices when available; otherwise, terminal market quotes were used (Virginia Marketing News Service, 1998, 1999). Terminal market prices were adjusted downward by subtracting sales and commission costs (20\%) and transportation costs (Sterrett et al., 1996). Return was calculated by subtracting the cost of production, grading and packing, and field clean-up from total value of the crop. Since the cost of land varies depending upon rent or ownership and the cost of management will vary between operations and should be proportioned among enterprises within an operation, the calculated return excludes these expenses (Sterrett et al., 1996). Statistical analyses of the production and economic variables were completed using the general linear model procedure. (SAS/STAT, 1999). Data were analyzed separately by years. Due to heterogeneous error variances and lack of a suitable transformation of the data to address this problem, data were not subsequently combined for further analysis (Table 2).

\section{Results and Discussion}

Yield. Total and marketable yields for the std, std-fum, and narrow beds were similar in 1998, with higher yields in the summer and fall-2 crops compared to the bridge and fall-1 crops regardless of treatment (Fig. 1A). Yields 
1998

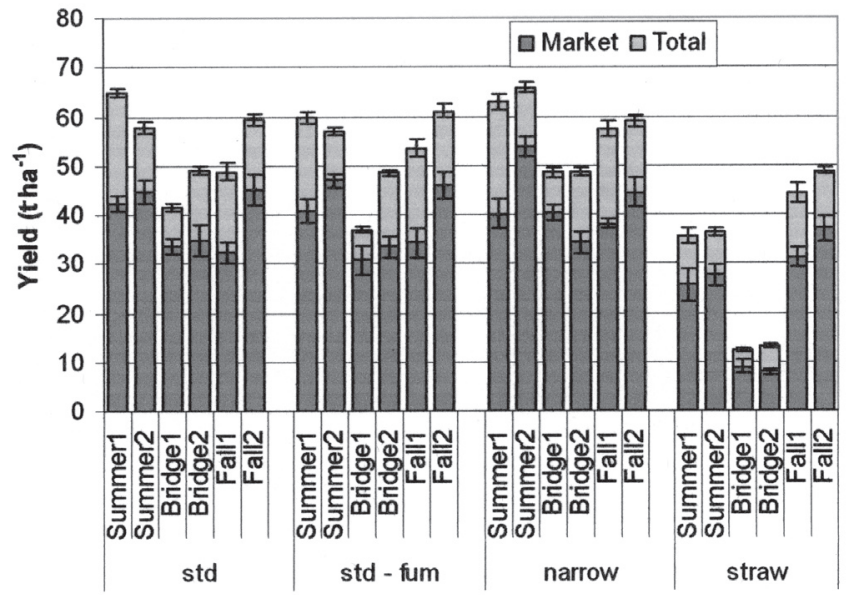

1999

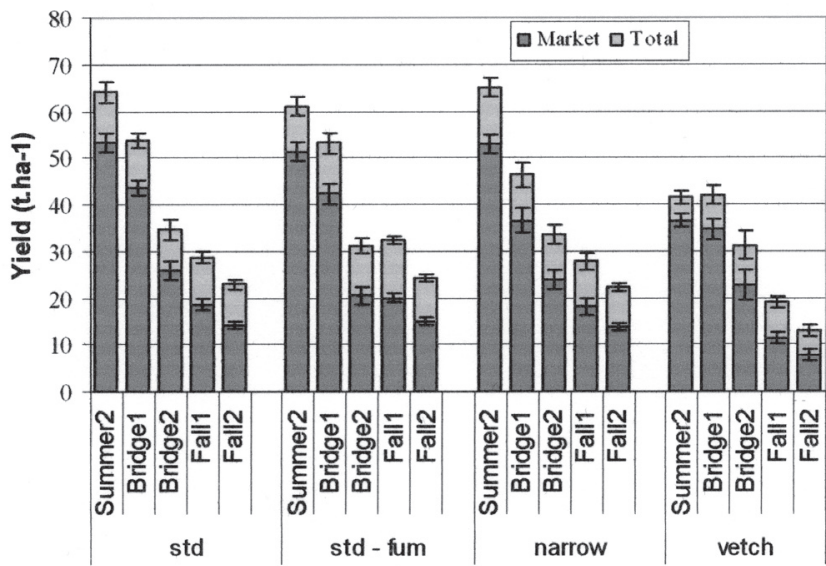

1998

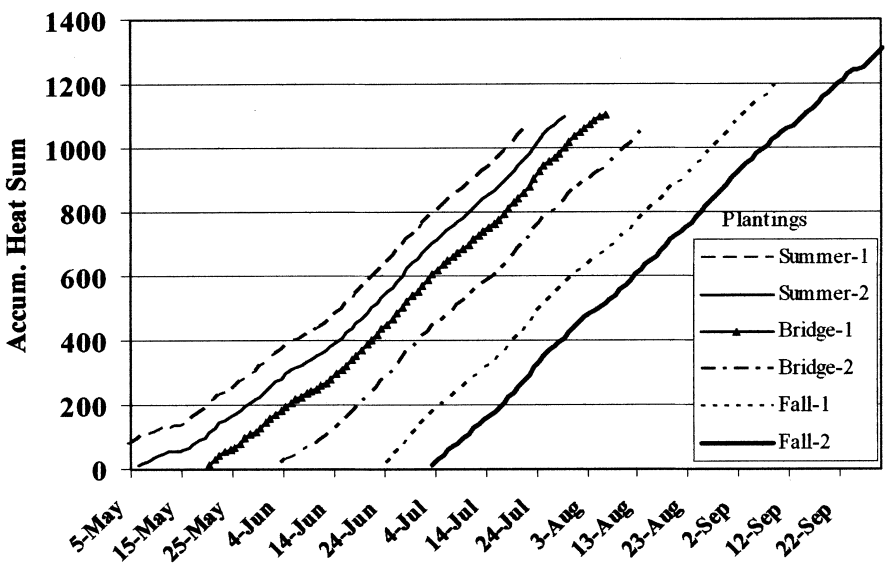

Fig. 1. Marketable and total yield of green-pack tomatoes for six plantings in 1998 (A) and five plantings in 1999(B). Straw used in 1998 instead of vetch because excessive rain in the fall of 1997 prohibited establishment of vetch cover crop. Analysis of variance: planting $\times$ on-bed treatment in 1998 and 1999 significant at $P=$ 0.01 . Values represent mean $\pm \mathrm{SE} ; \mathrm{n}=8$.

in the three plasticulture treatments were greater than those in the straw mulch in all plantings. In 1999, yields in the vetch mulch were lower than those in the plasticulture treatments for summer-1, bridge-1, fall-1 and fall-2 plantings, but yields were similar in the bridge- 2 crop (Fig. 1B). Plants grown in organic mulches were shorter with smaller leaves than those grown in plasticulture (data not shown). The effect of between-bed strategies differed between years. In 1998, total yield was reduced from $52.1 \mathrm{t} \cdot \mathrm{ha}^{-1}$ for clean culture to $46.4 \mathrm{t} \cdot \mathrm{ha}^{-1}$ for millet $(P \leq$ 0.001 ), but marketable yield was not reduced. Between-bed management did not affect yields in 1999 (data not shown). However, the cost of production increased by $\$ 71 /$ ha for millet seed and planting. Weeds within the millet cover were controlled by mowing in this study, which would not be feasible on a large scale. Broad leaf weed control in the between-bed cover must to be addressed before commercial acceptance.

Early temperatures were cooler for the summer-2 crop in 1999 compared to those in 1998 as seen in the slower accumulation of heat units
(Fig. 2). However, greater total heat units were accumulated by the last harvest of the summer2 and bridge- 1 and bridge- 2 crops in 1999. Maximum temperature exceeded $32.2{ }^{\circ} \mathrm{C}$ on $21 \mathrm{~d}$ during June, July and August in 1998 and on $32 \mathrm{~d}$ during the same period in 1999. High temperatures during fruit set and development, as well as increased weed competition in the organic mulch contributed to the yield reduction in 1999. The decline in yield in all treatments in fall-2 compared to fall-1 planting in 1999 reflects the loss of the last harvest of fall-2 from hurricane damage.

The improved growth in the organic mulch in the bridge- 2 crop may be attributable to increased biomass production before desiccation compared to the summer-1 crop. However, vetch is known to decompose rapidly, losing much of the residue $\mathrm{N}$ within 4 weeks of desiccation (Wagger, 1989). The possible nitrogen advantage of the vetch mulch was most likely lost to the fall- 1 and fall- 2 crops since decomposition of the vetch mulch was nearly complete before these late crops were planted. Lower yields in the organic mulches early in the season may also be attributed to reduced root activity in cooler soil temperatures. Teasdale and Mohler (1993) reported reduced daily maximum temperature and daily soil temperature amplitude with cover crop residue while light transmittance through hairy vetch residue increased over time as the residue decomposed. Otherorganic mulches that
1999

Fig. 2. Accumulated heat units (base $10^{\circ} \mathrm{C}$ ) acquired by each planting in 1998 (top) and 1999 (bottom) from planting to last harvest. Wet weather prevented timely planting of the first planting in 1999. Plantings scheduled about 2 weeks apart.

do not pose the potential weed problem of vetch could be grown longer before desiccation and may be more suitable for fall tomato production in eastern Virginia.

Estimated crop value. Estimated value of the summer crops in the plasticulture treatments were higher than those of the bridge and fall crops (Fig. 3). Yield, price and size distribution influenced the estimated value of the 1998 summer crops since prices were higher for extralarge fruit during much of the harvest period in 1998(Virginia Marketing News Service, 1998). The percentage of extra-large fruit increased from $16 \%$ to $23 \%$ from summer- 1 to summer- 2 crops, then fell to $<6 \%$ for the fall plantings of 1998; few extra-large fruit were harvested in 1999 (Sterrett et al., 2001). There was no price advantage for extra-large fruit in 1999 (Virginia Marketing News Service, 1999) as there were too few extra-large fruit in commercial plantings to establish reliable price estimates.

The influence of between-bed cover on crop value was inconsistent in 1998 (Fig. 3A). Establishment of millet between beds resulted in significantly lower crop value for several planting $\times$ on-bed mulch combinations, including std-fum and organic mulch in summer-1, 

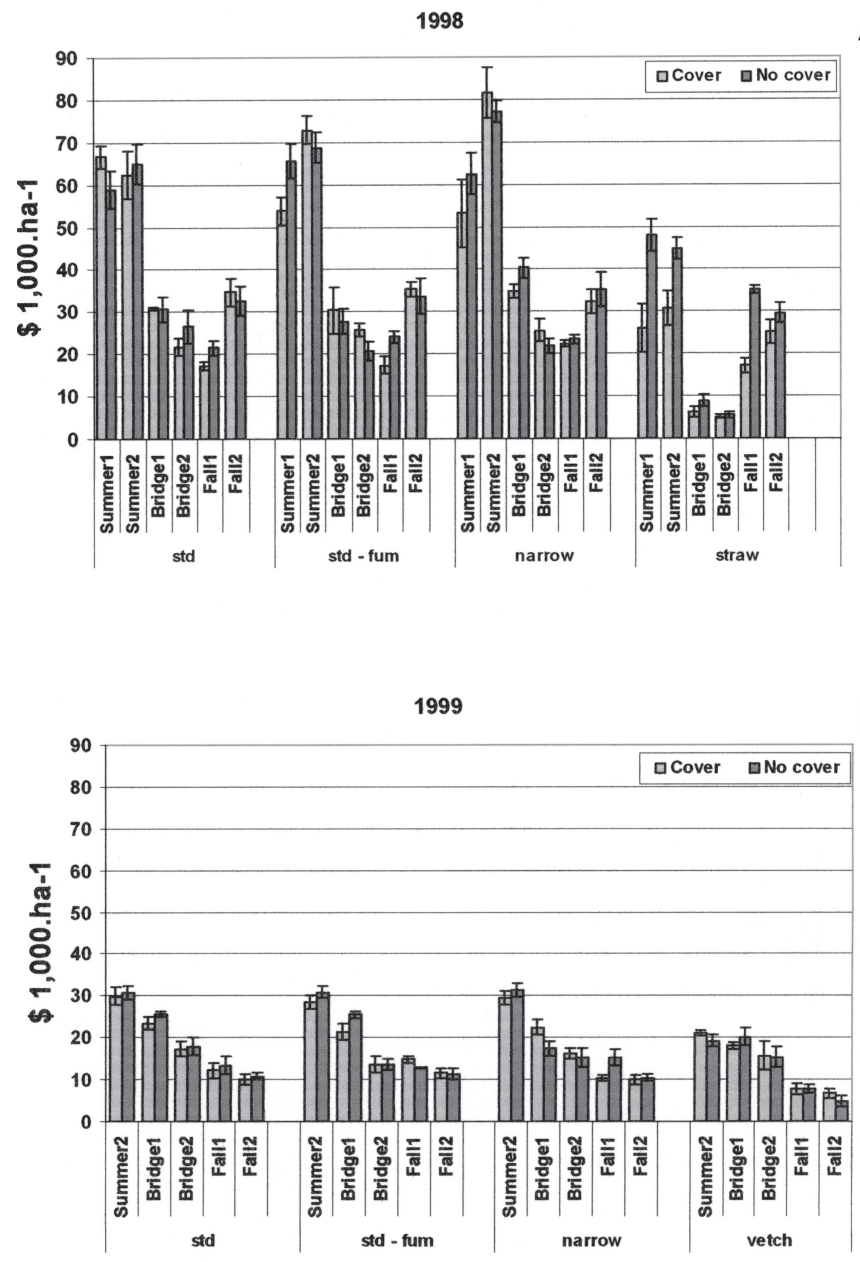

Fig. 3. Estimated crop value of green-pack tomatoes in 1998 (A) and 1999 (B). Straw used in 1998 instead of vetch because excessive rain in the fall of 1997 prohibited establishment of vetch cover crop. Analysis of variance: planting $\times$ on-bed treatment $\times$ between-bed cover $( \pm$ cover $)$ in 1998 and 1999 significant at $P=0.02$ and 0.04 , respectively. Values represent mean $\pm S E ; n=8$.

organic mulch in summer-2, narrow in bridge-1, and organic mulch in fall1 plantings. Milletalso reduced value in the fall-1 crop for std, std-fum, and organic mulch. Establishment of millet between the beds had little effect on estimated value in 1999, except for improvement in the bridge-1/narrow bed and reduction in the fall1/narrow bed (Fig. 3B). Since tomato yields were severely impacted by the heat stress of 1999, the influence of the between-row treatments may be less apparent than under the more optimal temperatures of 1998. Reduction of sediment movement between beds is important for improving water quality leaving the tomato field but the potential reduction in crop value is a concern. The influence of establishing a cover crop between beds then desiccating after 3 to 4 weeks needs to be evaluated.

Return to land and management. Estimated return was lower with organic mulch in the summer- 2 , bridge- 1 and bridge- 2 plantings compared to the plasticulture treatments without millet in 1998 (Fig. 4A). Return was reduced when millet was planted with the organic mulch
$A$ in all plantings (Fig. 4B). In 1999, millet had little impact on return. However, return for the summer-2 crop with plasticulture was greater compared to organic mulch (Fig. $4 \mathrm{C}$ and $\mathrm{D})$. In organic mulches, the substantially lower return reflects the delayed maturity in the early plantings, reduced plant growth, and increased weed competition for all plantings (data not shown). High yield of large fruit is essential, particularly

B for the early plantings, to establish a strong position in the market place. Reduced return in organic mulch treatments reflected both reduced yield and reduced fruit size (Sterrett et al., 2001). Davis and Estes (1993) also found significant differences in net returns when comparing combinations of tomato cultural management practices, particularly when those practices reduced the percentage

of extra-large fruit.

Return was lower in the bridge- 1 with std and std-fum treatments with millet than without, but was negative for most later planting $x$ on-bed combinations. The return from bridge crops in this growing area is often low. However, the bridge crops are considered essential by some growers to maintain their position in the marketing arena. The estimated return from the fall crops was directly related to the prevailing prices, which were low in 1998 and 1999. The influences of on-bed and between-bed management strategies reflected the estimated value of the crops and the additional cost of establishing and maintaining the millet cover. Negative returns to land and management for many of the planting/treatment combinations in 1999 illustrate the potential risk associated with this high-value crop. Wu et al. (2002) also found greater yield fluctuation in crops grown in hairy vetch than in plasticulture, concluding that plasticulture exhibited the least economic risk and was therefore the most economically stable method for growing tomatoes.

The production effectiveness and economic impact of some of the other BMPs suggested by Courter et al. (1998) varied. Reduced cost of production associated with omitting fumigation was not a major savings in either year. Pest pressure from yellow nutsedge and root knot nematode was not serious in these plots but can be significant in some commercial fields; the decision to omit fumigation in a given field would need to be driven by past cropping experiences. Also, potential crop loss would be increased in seasons with high disease pressure. The returns from narrow beds were generally similar to those of the standard plasticulture treatment. Narrow beds may have potential for increasing the surface area per hectare that is uncovered thereby increasing the potential for water infiltration and reducing off-site sediment movement. However, careful irrigation management would be needed to minimize soil moisture stress and produce a high quality crop. Additional research is needed to determine the effectiveness of between-bed strategies using cover crops desiccated early in the growing season as a potential management practice for reducing off-site sediment movement.

Delayed maturity of plants grown in organic mulch in the early plantings, combined with the reduced plant growth and increased weed competition for all plantings in organic mulch is reflected in the substantially lower return in this study. Teasdale and Abdul-Baki (1998) have reported greater biomass production with mixtures of rye and hairy vetch or crimson clover (Trifolium incarnitum L.), with reduced weed growth but without yield reduction for a June planting (equivalent to a bridge crop in Virginia). Excessive decomposition of the vetch for the Eastern Shore fall plantings suggests additional studies of other species are needed to gain the weed suppression reported by Teasdale and Abdul-Baki (1998).

\section{Conclusions}

The use of organic mulch for the summer tomato crop was generally not an economically viable alternative strategy for staked tomato compared to plasticulture treatments. However, crop yield and return for narrow beds was similar to the plasticulture standard and would reduce the impermeable surface area within the field. Reduced return from the bridge and fall crops indicated that more cost effective management strategies are needed for the later plantings in this growing area. Other between-bed BMPs need to be evaluated for plasticulture tomato production in eastern Virginia because of the reduction in estimated return with millet in some planting $\times$ on-bed treatment combinations and the increased management needed with mown millet.

\section{Literature Cited}

Abdul-Baki,A.A. and J.R. Teasdale. 1997. Sustainable production of fresh-market tomatoes and other summer vegetables with organic mulches. USDA Res. Serv. Farmers Bul. 2279:1-23.

Arnold, G., M. Luckenback, J.M. Roberts, M. Newman, E. Shumann, M. Unger, and G. Vadas. 2001. Fate and effects of crop protectants from tomato cultivation on living resources in tidal creeks. Final Rpt. Va. Dept. Agr. Consumer Serv. p. 1-215.

Bhella, H.S. 1988. Tomato response to trickle irrigation and black polyetheylene mulch. J.Amer. Soc. Hort. Sci. 113:543-546.

Bogle, T.K., T.K. Hartz, and C. Nunex. 1989. Comparison of subsurface trickle and furrow irrigation on plastic-mulched and bare soil for tomato production. J. Amer. Soc. Hort. Sci. 114:40-43.

Bottcher, A.B., K.L. Campbell, L.W. Miller, D.W. Sweeney, and S.J. Locascio. 1982. Crop and ir- 

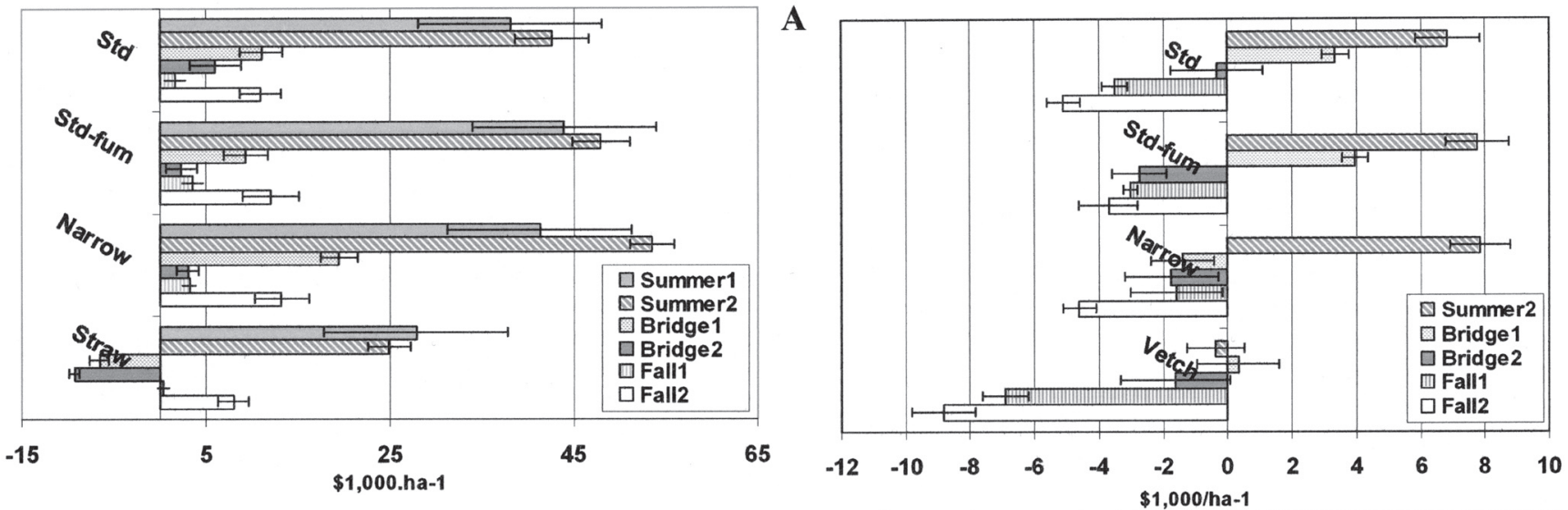

C
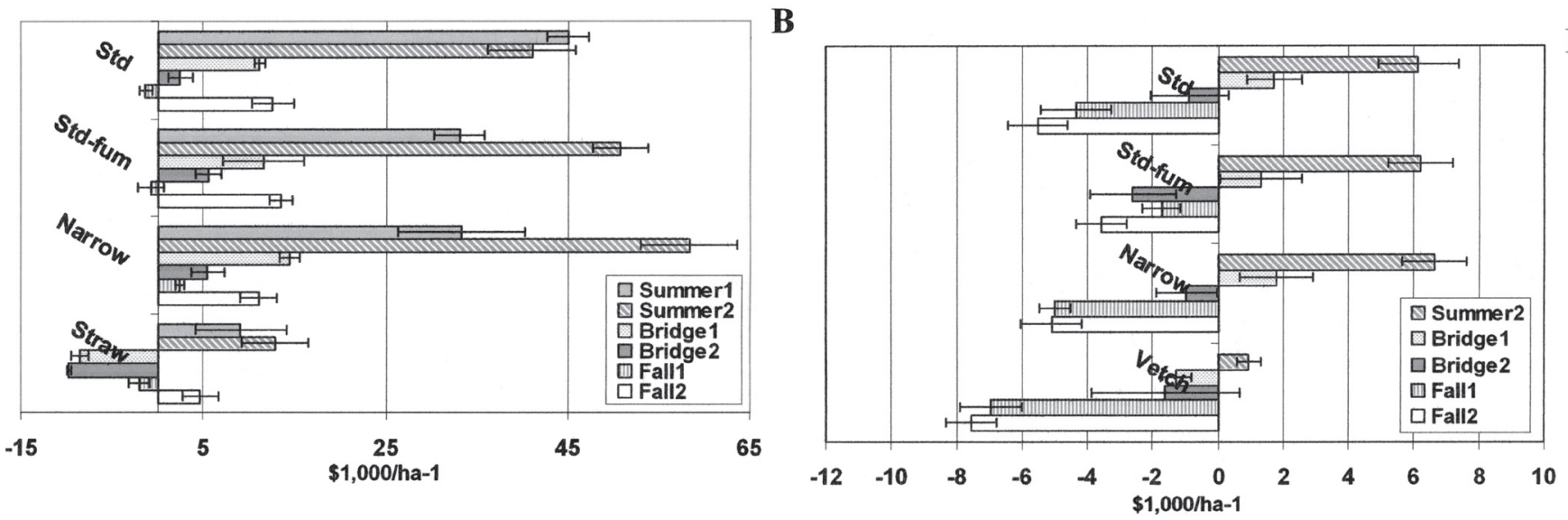

Fig. 4. Return to land and management of green-pack tomatoes in 1998 without between-row cover (A) or with cover (B) and in 1999 without cover $(\mathbf{C})$ or with cover (D). Since wet weather in 1999 prevented planting of the summer-1 crop, the dates follow the same designation starting with summer-2. Cost of land rental/taxes and salary/benefits for the grower is excluded from these calculations. Analysis of variance: planting $\times$ on-bed treatment $\times$ between-bed cover in 1998 and 1999 significant at $P=0.01$ and 0.04 , respectively. Values represent mean $+\mathrm{SE} ; \mathrm{n}=4$.

rigation management for improved off-site water quality, p. 354-366. In:E.G. Kruse, C.R. Burdick, and Y.A. Yousef (eds.). Proc. Specialty Conf. Environ. Sound Water and Soil Mgt., Orlando, Fla., 20-23 July.

Brault, D., K.A. Stewart, and S. Jenni. 2002. Growth, development, and yield of head lettuce cultivated on paper and polyethylene mulch. HortScience 37:87-91.

Bratsch,A.D., T.P.Kuhar, S.B.Phillips, S.B. Sterrett, C. Waldenmaier, and H.P. Wilson. 2004. Commercial vegetable production recommendations. Va. Coop. Ext. Publ. 456-420.

Courter, J.C., D.G. Blankenship, A.J. Anthony, C.S. Crafton, F.L. Daniel, C.A. Lunsford, M.A. Lawson, and S.D. Mallette. 1998. Report of the interagency plasticulture task force: study of plasticulture and related water quality management issues. Commonwealth Va. House Document No. 44.

Davis, J.M. and E.A. Estes. 1993. Spacing and pruning affect growth, yield, and economic returns of staked fresh-market tomatoes. J. Amer. Soc. Hort. Sci. 118:719-725.

Jaworski, C.A., S.C. Phatak, A.W. Johnson, and S.M. McCarter. 1981. Tomato production and soil pest control in relation to width of fumigated and mulched bed and soil fumigation rate. HortScience 16:667-669.

Kelly, T.C., Y.C. Lu, A.A. Abdul-Baki, and J.R. Teasdale. 1995. Economics of a hairy vetch mulch system for producting fresh-market tomatoes in the mid-Atlantic region. J. Amer. Soc. Hort. Sci. 120:854-860.

Morse, R.D. 2001. No-till vegetable production-Its time is now. HortTechnology 11:43-48.
Perry, K.B.and D.C. Sanders. 1986. Tomato yield as influenced byplantprotection systems. HortScience 21:238-239.

SAS/STAT. 1999. SAS/STAT user's guide. V8. vol 1-3, Cary, N.C.

Scott, G.I., M.H. Fulton, M.C. Crosby, P.B. Key, J. Donaugomah, J.T. Waldren, E. Dstrozier, C.J. Louden, G.T. Chandler, T.F. Bidleman, K.L. Jackson, T.W. Hampton, T. Hofman, A. Shulz, and M. Bradford. 1990. Agricultural insecticide runoffeffects on estuarine organisms: corrletating laboratory and field toxicity test, ecophysiology bioassays, and ecotoxicological biomonitoring. Report to U.S. EPA, Gulf Breeze, Fla.

Sterrett, S.B., H.E. Hohlt, and C.P. Savage, Jr. 2001. Alternative strategies for tomato production, p. 535-541. Intl. Conf. Plastics in Agriculture, Hershey, Pa.

Sterrett, S.B., S.D. Thornsbury, C.W. Coale, S.G. Sturt, and J.W. Mapp. 1996. The process for evaluating agricultural alternatives: An eastern shore Virginia example. Va. Coop. Ext. Publ. 448-220/REAP R022.

Teasdale, J.R. and A.A. Abdul-Baki. 1995. Soil temperature and tomato growth associated with black polyethylene and hairy vetch mulches. J. Amer. Soc. Hort Sci. 120:848-853.

Teasdale,J.R. andA.A.Abdul-Baki. 1998. Comparison of mixtures vs. monocultures of cover crops for fresh-market tomato production with and without herbicide. HortScience. 33:1163-1166.

Teasdale, J.R. and D. Colacicco. 1985. Weed control systems for fresh market tomato production on small farms. J. Amer. Soc. Hort Sci. 110:533-537.

Teasdale, J.R. and C.L. Mohler. 1993. Light trans- mittance, soil temperature and soil moisture under residue of hairy vetch and rye. Agron. J. 85:673-680.

U. S. Dep. Agr. 1992. Fresh tomatoes - Shipping point inspection instructions. Agr. Mktg. Serv. HU-115-2(a).

Virginia Marketing News Service. 1998. Fruit and vegetable bulletin. VA Dept. Agr. Consumer Sci vol. 46, No. 21-43.

Virginia Marketing News Service. 1999. Fruit and vegetable bulletin. VA Dept. Agr. Consumer Sci vol. 47, No. $24-42$.

Van Derwerken, J.E. and D. Wilcox-Lee. 1988. Influence of plastic mulch and type and frequency of irrigation on growth and yield of bell pepper. HortScience. 23:985-988.

Wagger, M.G. 1989. Time of desiccation on plant composition and subsequent nitrogen release from several winter annual cover crops. Agron. J. 81:236-241

Wien, H.C. and P.L. Minotti. 1987. Growth, yield, and nutrient uptake of transplanted fresh-market tomatoes as affected by plastic mulch and initial nitrogen rate. J. Amer. Soc. Hort. Sci. 112:759-763.

Wolfe, M.L.,B.B. Ross, J.F. Diem, T.A.Dillaha, III, and K.A. Flahive. 2002. Protecting water quality: Best management practices for crops grown on plastic mulch in Virginia. Va. Coop. Ext., Blacksburg,Publ. 442-756.

Wu, S, Y Lu, D.J. Mills, C.B. Coffman, and J.R. Teasdale. 2002. Economic evaluation of alternative production systems for fresh-market tomatoes in the mid-Atlantic region. J. Veg. Crop Prod. 8:91-107. 